\title{
Southern range dynamics of Canada lynx over seven decades
}

\author{
Robby Marrotte ${ }^{1}$ and Jeff Bowman ${ }^{2}$ \\ ${ }^{1}$ Trent University \\ ${ }^{2}$ Ontario Ministry of Natural Resources and Forestry
}

October 14, 2020

\begin{abstract}
The range of the Canada lynx (Lynx canadensis) has contracted substantially from its historical range prior to the 19th century. Using harvest records, we found that the southern range of the lynx in Ontario in the late 1940s collapsed and then in a short period of time increased to its largest extent in the mid-1960s where the lynx range spread south of the boreal forest for a decade. After this expansion the southern range contracted northwards beginning in the 1970s. Most recently, there has been a slight expansion between 2010-2017. We have attributed these dynamics on the southern range periphery to the fluctuation of the boreal lynx population in the core of the species' range. In addition, connectivity to boreal lynx populations and snow depth seemed to condition whether the lynx expanded into an area. However, we did not find any evidence that would suggest that these changes were due to anthropogenic disturbances or competition. The boreal lynx population does not reach numbers as it once did, consequently we likely will not see large expansions of the southern lynx range as in the mid-1960s. Our results suggest that southern lynx range in Ontario have been driven by the magnitude of the boreal lynx population cycle, connectivity to the boreal forest and snow conditions. Therefore, it is quite unlikely that southern lynx population in the Great Lakes will ever recover, since the warming climate and forestry practices are causing a northward contraction of the boreal forest and likely with it the core lynx populations.
\end{abstract}

\section{Introduction}

Over the past century the range of many species has changed, often attributed to climate change and land cover modification (Thomas 2010, Laliberte and Ripple 2004, Walther et al 2002). A species can respond to environmental changes by exploiting resources at the extremities of its niche breadth (Sexton et al. 2017), by phenotypic plasticity (Valladares et al. 2014, Nicotra et al. 2010), or by adaptation (Williams et al. 2008). However, the rate at which current conditions are changing might make adaptation impossible for many species because the process of natural selection is too slow (Davis and Shaw 2001). Consequently, species will have to track their bioclimatic niche (Visser 2008) the ability to do so will be an essential characteristic influencing future biodiversity (Bell and Gonzalez 2011, Schloss et al. 2012, Travis et al. 2013).

Terrestrial species that have ranges near the poles will be limited in their ability to track climate because they are limited by the availability of space to move to higher latitudes (Kerr and Packer 1998). Therefore, many unique cold adapted species will eventually perish unless they somehow adapt to much warmer conditions and to new biotic interactions. Understanding how and why the warmer range edge of cold adapted species has been changing would help us in making better informed conservation decisions, since anthropogenic change is not slowing down.

The Canada lynx (Lynx canadensis) is an iconic carnivore that largely resides in the boreal forest of North America and its northern range has some expansion potential into northern taiga landscapes but is generally bounded by tundra and the Arctic Ocean (Poole 2003). The lynx is a habitat specialist because it 
almost exclusively preys on snowshoe hares in the boreal forest (O'Donoghue et al. 1998). Consequently, its population dynamics are highly coupled to the 8-11 year population cycle of the snowshoe hare, mirroring it with a 1-2 year delay (Poole 2003). Since presettlement times the Canada lynx range has contracted by $40 \%$ (Laliberte and Ripple 2004). However, most of this range reduction took place prior to the $20^{\text {th }}$ century and was attributed to unregulated harvest and habitat loss due to land clearing during European colonization (de Vos 1952, de Vos 1964, Hovinget al. 2003, McKelvey 2000, Poole 2003).

Canada lynx are predominantly found in areas where snowshoe hare density is above 0.5 per hectare (Zahratka and Shenk 2008, Hodges et al.2009, Berg et al. 2012, Ivan et al. 2014). In the southern periphery of the lynx range, hare population densities have declined compared to historic levels (Aubry et al. 2000, Hodges 2000, Murray 2000) and this most likely accounts for the contraction of the lynx from its historic range (Poole 2003). Following years with high peak hare abundance, Canada lynx appear to migrate from range core to range periphery as a result of density dependent dispersal (McKelvey et al. 2000). Such dispersal pulses might lead to higher occupancy of the southern range periphery (McKelvey et al 2000, Murray et al.2008). Consequently, lower peaks in hare abundance might decrease the likelihood of dispersal of lynx into the southern periphery (Poole 2003). Southern dispersal might also be limited in some locations by connectivity with the range core (Ruggiero et al. 2000, Buskirk 2000, Walpole et al. 2012).

The warming climate might indirectly impact the lynx through its main food source the snowshoe hare. The timing between molt and season change for the snowshoe hare is important in decreasing predation rates (Zimova et al. 2016). A changing snow regime could increase snowshoe hare predation rates by increasing the rate of mismatch between snowshoe hare molt and season change. Increased predation rates might also reduce the amplitude of the hare cycle (Krebs 2010).

Climate change will also open formerly inhospitable habitat to new species in the lynx range. Bobcats (Lynx rufus ) and coyotes (Canis latrans ) have smaller feet than Canada lynx, consequently they cannot support as much weight as lynx in deep snow without sinking (Parker et al. 1984). This might be one factor that has hindered the bobcat from invading Canada lynx territory in the past (Marston 1942, McCord 1974, Murray et al. 2008, Parker et al.1984). However, since the climate is warming, and snow depths across the southern periphery of the lynx range are shallower, southern competitors might be less hindered by snow, increasing their competitive potential (Buskirk et al. 2000, Ruediger et al. 2000, Scullyet al. 2018). In fact, Parker et al. (1984) found that after several years of low snow the bobcat invaded the lowlands of Cape Breton while the Canada lynx left the area. Marrotte et al.(2020a) found that deep winter snow in the Great Lakes region limited bobcat expansion northward, suggesting that greater expansion will result from additional climate warming.

The lynx once occurred in 24 of the United States (McKelvey 2000), but currently only occurs in 7 (US Fish and Wildlife Service 2017). As a result, the lynx is designated as 'threatened' in the contiguous United States (US Fish and Wildlife Service 2000). Despite the range contraction, its protection status is being debated and it might be removed from the list of endangered species in the United States. In Canada, the lynx occupies $95 \%$ of its historic range (Poole 2003). However, it is designated as provincially endangered in Nova Scotia (Parker 2001), and New Brunswick (New Brunswick Endangered Species Regulation 2013) and was extirpated from Prince Edward Island (Poole 2003). Further analysis has demonstrated that the range of lynx in British Columbia has been stable since the 1930s (Gooliaff and Hodges 2018). In contrast, the lynx range in Ontario appears to have contracted northwards by $175 \mathrm{~km}$ from 1972 to 2010 (Koen et al. 2014).

We estimated the past extent of the Canada lynx southern range in Ontario, Canada using harvest records and then determined whether the spatial-temporal patterns could be attributed to snowshoe hare and boreal lynx population dynamics, connectivity, climate, land use and competition. We predicted that years with low Canada lynx abundance in the boreal forest were associated with a reduction in the extent of the southern lynx range. We also predicted that areas with high human disturbance, shallow snow, presence of competitors, and with low connectivity to boreal lynx populations were less likely to be part of the southern range. 


\section{Material and Methods}

\section{Study Area}

We defined the southern periphery of the lynx range as the southern margin of the boreal forest to areas south of the boreal forest where lynx occurred at least once between 1948-2017 in Ontario, Canada (Figure 1). To first identify the boreal forest, we used the spatial layer supplied by Natural Resources Canada that were derived from maps from the early 1970s to the late 2000s (Brandt 2009). We then defined our study area as the region where lynx have occurred south of the boreal forest and an additional band of southern boreal forest that extended 1 sampling unit (defined below) or $65 \mathrm{~km}$ north of the southern boundary of the boreal forest to account for uncertainty in both the boreal limit and the uncertainty in our harvest records. There were 3 distinct southern range zones in Ontario. The west and central zones are separated by Lake Superior and are also within $100 \mathrm{~km}$ of the boreal forest, whereas the east zone is further away. We used these zones to illustrate regional trends in range change, since these zones had different spatial and temporal patterns.

The southern lynx range periphery was predominantly found in the Great Lakes-St Lawrence Forest, which is a transition zone between the boreal and deciduous forest (Boucher et al. 2009). The Great Lakes-St Lawrence forest is dominated by white pine (Pinus strobus), red pine (Pinus resinosa), hemlock (Tsuga canadensis), beech (Fagus grandifolia), yellow birch (Betula alleghaniensis), and sugar maple (Acer saccharum ) (Rowe 1972).

\section{Harvest records}

Long term spatial data on terrestrial species are quite rare. Fortunately, wildlife agencies track furbearer harvest each year. Such records contain important information that can be used to monitor and study the change in range, spatial distribution, and population dynamics of several species that are harvested for their fur (Hayne 1949, Viljugrein et al. 2001).

Ecologists have used fur harvest data to address fundamental questions in ecology (Krebs et al. 1995, Keith 1963, Bulmer 1974, Elton and Nicholson 1942). There are, however, some issues with using fur returns. Trapping effort should be accounted for (DeVink et al. 2011, Dorendorf et al. 2016) and generally the location of capture is only available at a coarse geographic level.

The Ontario Ministry of Natural Resources and Forestry has been compiling furbearer trapping records since the beginning of the 20th century (Figure 2). A registered trapline system in Ontario began in the late 1940 s, and therefore, spatially referenced annual harvest records are available beginning in 1947. Trapping of furbearers in Ontario takes place within a township or on a trapline. Traplines are designated as areas on public land where trappers are licensed to harvest furbearers. Hereinafter we refer to townships and traplines as trapping units. We georeferenced these records using the appropriate trapping unit map for each harvest record.

\section{Spatial and temporal coverage}

Boundaries of trapping units changed occasionally due to regulation changes. Therefore, we divided the southern Canada lynx range into 370 equal area hexagons or sampling units of $2,731 \mathrm{~km}^{2}$. The area of these hexagons was based on the largest trapping unit found in the southern range between 1947 and 2017. We assigned each trapping unit to the hexagon that its centroid fell into. All the information in each trapping record was then aggregated to the sampling unit for each year. Of the 370 sampling units only 146 contained southern boreal trapping units. There were years where records were completely missing for all sampling units $(1969,1970,1975,1986,1989$ and 1991), years where many records were missing $(1947,1972$ and 1992) and other years where certain sampling units had the occasional missing record. Consequently, temporal coverage of sampling units varied from 65 years to only 4 years for the 71-year period between 1947-2017. 
Due to the variability of spatial and temporal coverage, we restricted our analysis to sampling units that had good temporal coverage. We first restricted our analysis between 1948 and 2017, because the trapline system was not completed yet in 1947 and therefore had limited spatial coverage. We further restricted our analysis to sampling units that had at least one lynx that was harvested from 1948 to 2017. Next, we omitted sampling units that had $>5$ years of consecutive missing data or at most 10 years of missing records. This left us with 82 of the previous 146 sampling units. Finally, we removed sampling units that contained on average less than $1000 \mathrm{~km}^{2}$ of trapping unit surface area between 1948-2017. These sampling units were all found either near the periphery of large water bodies, near political boundaries or near an area that had trapping restrictions (Provincial Parks or crown game preserves). This left us with a final sample size of 65 sampling units.

\section{Estimating the spatial and temporal range}

We used the R package 'mgcv' to fit Hierarchical Generalized Additive Models to estimate the probability of harvesting a Canada lynx within sampling units across space and time (Woods 2011). We first built several models that combined our effort predictors. We used thin plate smoothers for each predictor, since we expected a non-linear relationship. We also compared two different spatial-temporal tensor product smoothers (Augustin et al. 2013, Wood et al. 2013, Eickenscheidt et al. 2018, Zhou et al. 2019). In each spatial temporal structure, we modelled the yearly temporal variability with a cubic regression smoother. The spatial structure was modelled with a spatial discrete process using a Markov Random Field (MRF) or a thin plate (TP) smoother on the spatial coordinates.

We used Relative Maximum Likelihood to fit our models. We set the number of knots ' $\mathrm{k}$ ' to 5 for each effort predictor, to 65 for all spatial smoothers and to 40 for the year smoother. We set the spatial and temporal knots to high values based on our highest computational capabilities. However, the 'gam' function in the mgcv package will fit models using penalised likelihood to estimate parameters for each basis function, therefore increasing the number of knots simply makes computation longer and does not overfit the model. Some basis functions may be penalised to the point where their estimates are zero in the final model fit (Petersen et al. 2019).

We then estimated the range of the Canada lynx across space and time by predicting the probability of trapping a lynx with an average value of effort. We identified the areas that had at least a $50 \%$ chance of harvesting a Canada lynx for each year between 1948 and 2017.

\section{Trapping effort covariates}

We investigated 3 types of effort measures: trapping area or frequency, harvest, and market-based measures. Our trapping area or frequency-based measures were the total number of trapping units and the area covered by trapping units within each sampling unit each year. Our first harvest-based effort measure was the total number furbearers harvested. We also thought that the density of American marten (Martes americana) harvested on a trapline would be a good measure of trapping effort, since martens are sympatric with lynx, the fur is valuable, and might index trapper effort (Webb et al. 2008). The price of lynx fur is also an important factor that can govern harvest patterns of lynx (DeVink et al. 2011, Dorendorf et al. 2016). Our market-based measure was the average lynx pelt price from the previous year.

For all animal-based measures of effort we investigated the log of the absolute number, density, and the average number of animals across trapping units, since the number of animals trapped varied exponentially between trapping units. In total we had 9 effort predictors, but we did not investigate models that combined total furbearer harvest and American marten harvest, since these measures were not independent. We also only investigated models that included the total number of trapping units, the area occupied by those trapping units, and the average pelt price. Consequently, we compared 6 different effort models to find the best model that would likely account for effort bias in harvesting a lynx. 
We calculated the yearly average price of lynx pelts that originated from Ontario using the furreturn summaries from a variety of sources. We gathered summaries collected by Statistics Canada (http://www5.statcan.gc.ca; CANSIM Table 003-0013). The time series ranged from 1970 to 2011, but most of the data from 2010 to 2017 were missing. Therefore, we used summaries provided by the Fur Institute of Canada for 2010-2017 (www.fur.ca). We then added data from the earlier period 1948 to 1970 provided by Novak (1987a and 1987b).

We then corrected for inflation using the Consumer Price Index (CPI) for the province of Ontario also available on the Statistics Canada website (statcan.gc.ca; CANSIM Table 326-0021). For each year we multiplied the average pelt price by the 2019 CPI and divided these values by the CPI of their appropriate year. This adjusted the average pelt prices to 2019 Canadian Dollars. In our analysis we used the adjusted average pelt price of the previous year for the current year of observation. The assumption is that trappers observed a high pelt price and are more likely to harvest a lynx in the following year.

\section{Testing hypotheses of range change}

We were interested in understanding how the area of the southern range fluctuated over space and time in accordance with different hypotheses. To simplify our analyses, we broke up our subsequent analyses into both spatial and temporal tests.

To test spatial hypotheses, we summed the number of times each sampling unit was part of the lynx range between 1948-2017. We then compared these values to each spatial predictor while we controlled for the influence of all other predictors with a partial Spearman rank correlation. We used a nonparametric correlation coefficient, because the response variable and all the covariates were not normally distributed. To test our temporal hypotheses, we calculated the area occupied by the southern lynx range each year and compared each temporal predictor to this time series. We investigated temporal lags of up to 2 years. Temporal stationarity is an important assumption for the association metric to be valid, therefore we calculated the between year differences for all time series (Priestley 1988). We then estimated associations with a Pearson correlation coefficient. We resampled without replacement our observations 9999 times to calculate p-values. We then adjusted our p-values to account for multiple tests using a Bonferroni correction.

\section{Spatial and temporal predictors}

We calculated the distance to boreal forest by summing the straight-line distance between the edge of each sampling unit and the closest boreal forest. For human disturbance we used the major roads in the Ontario Road Network layer as a proxy variable (LIO; geohub.lio.gov.on.ca). For each sampling unit we calculated the distance to the nearest road in kilometres.

We estimated a hare time series by gathering hare abundance data from the Ontario Ministry of Natural Resources and Forestry (OMNRF Unpublished). Monitoring of hare populations is undertaken in the fall (October) through an array of pellet count plots in several locations across the province (e.g., Bendell and Young 1995). The longest running snowshoe hare population monitoring (since 1986) is in Gogama, Ontario (Figure 1). These data originated from many plots that we aggregated to a single measure that indicates the average number of hare pellets. The number of pellets should indicate the density of hare found in nearby boreal forest (Krebset al. 2001).

We built the boreal forest lynx population time series by gathering all trapping records located in the boreal forest and summed these by year. We wanted our boreal lynx population index to be independent from our response data, therefore we removed all records used to estimate the lynx range that were outside of the boreal forest (i.e., all records within our hexagonal study areas). We also ln-transformed these boreal lynx harvest values to correct for harvest bias (Royama 2012).

We built a snow map and time series from weekly measurements gathered from the Snow Network for Ontario Wildlife (wildliferesearch.ca/snow; Warren et al. 1998). For each year, we calculated the SDI (Snow 
Depth Index), which is the sum of all weekly measurements collected at a station over the winter months. We interpolated the data across our study area using ordinary kriging using the 'automap' package in $\mathrm{R}$ (Hiemstra and Hiemstra 2013). We then calculated the average SDI for each sampling unit for our spatial map and we calculated the average annual SDI for each year between 1952 and 2017. We removed stations that had less than 16 measurements during the year. This is equivalent to 4 months of winter and captured some early spring and late fall snow events.

We built maps of the occurrence of competitors and their associated time series by counting the number of times each species (bobcat and coyote) was present in the harvest records in each sampling unit over time and space. For our spatial map we summed the number of years that a competitor was found in each sampling unit. For our time series we summed the number of sampling units that each species was present in during each year.

We performed all our spatial processing and modelling in R version 5.5.1 (R Core Team 2014). All spatial layers were projected to MNRF Lambert conformal conic (EPSG:3161).

\section{Results}

The model that could best account for the effort of harvesting a Canada lynx and the spatial temporal process in the southern periphery of Ontario, Canada included the log transformed total number of furbearers harvested and a thin plate smoother on the spatial coordinates (Table S1). This model was 20.914 AIC units lower than all other models and its $\mathrm{AIC}_{\mathrm{w}}$ was 1.000 . The spatiotemporal effort model had an adjusted $\mathrm{R}^{2}$ of 0.586 and a deviance explained of $54.1 \%$. Other than the total number of furbearers harvested, the 3 other effort related predictors followed linear relationships (Figure S1). The additive effect of the number of trapping units, the total area, and the average price were not as important than the total number of animals harvested. The probability of harvesting a lynx decreased with the total area harvested while the 3 other predictors had a positive relationship. Also, the influence of lynx pelt price was weak compared to the other predictors.

The probability of harvesting a Canada lynx south of the boreal forest across Ontario changed through time (Figure 3). During the late 1940s and the early 1950s, the likelihood of harvesting a lynx was at its lowest. However, in the mid-1960s the odds peaked across the southern range and even trapping units found in the east had a high probability. After this peak lynx period, it then became unlikely to harvest a lynx in the east and this pattern continued to 2017. The odds of harvesting a lynx peaked in both the west and central zones in the early 1960s and again in the mid-1970s, then declined until the 2000s and increasing slowly until 2017 to an overall probability of harvest higher than in previous years.

To get a better idea of the range dynamics, we calculated the occupied area of the southern range of each zone for each year (Figure 4). In 1950 the total extent of the southern lynx range was at its lowest and occupied a total are of $19,118.2 \mathrm{~km}^{2}$. The extent of the range peaked between 1963-1964 and occupied a maximum area of $147,483.5 \mathrm{~km}^{2}$. This was an area $7.7 \mathrm{x}$ larger than during the crash in the late $1940 \mathrm{~s}$. From 1970 onwards, the southern range varied much less in size compared to previous years. It declined between 1970 and the late 1980s, but gradually increased until 2017 to a size comparable to the early 1970s. There were also a few notable decreases in range in the periods 1965-1972, 1983-1992 and 1995-2002.

In general, all 3 zones (west, central, and, east) followed similar patterns. However, from 1957 to 1964 the east zone increased from $5,462.4$ to $30,042.9 \mathrm{~km}^{2}$, which was a 6 -fold increase and occupied most of the Lanark and Renfrew County just east of Ottawa (Figure 3). This increase was not as dramatic in the west and central zones, where there was only a 1.5 - and 1.3 -fold increase. Although, these two northernmost ranges were already closer to their maximum extent of $65,548.2$ and $54,623.5 \mathrm{~km}^{2}$, consequently they could not have increased as intensely during this period. A smaller range contraction in this same Lanark and Renfrew County area also occurred in 1971 to 1973. 
From the late 1950s to 2017, the west and central zones varied by $24,580.6[40,967.6-65,548.2]$ and $16,387.0$ $\mathrm{km}^{2}[38,236.5-54,623.5]$. The west zone reached its maximum area more recently in 2013 and 2017, whereas the central zone reached its maximum area multiple time in the periods 1960-1967 and 1970-1976. The east zone varied quite differently. It increased dramatically twice in the period 1959-1973 and never reached these levels again. After this point the range varied between 0 and $8,193.5 \mathrm{~km}^{2}$.

We calculated the number of years each sampling unit was within the lynx southern range. Sampling units in the south were less frequently part of the Canada lynx range (Figure S2). In the east zone, sampling units were only part of the range on average 8.7 years over the 70 -year time period. In contrast, the west and central zones were part of the range 48.2 and 58.1 years, respectively.

We predicted that undisturbed areas with deep snow, an absence of competitors, and close proximity to the boreal forest were more likely to be part of the southern range. We found that 2 of 5 of these relationships met our initial expectations (Table 1). Sampling units that were more frequently found within the Canada lynx range were closer to the boreal forest and had deeper average annual snow. We also predicted that years with large numbers of hare and lynx in the boreal forest, low number of competitors, and deep snow increased the extent of the southern Canada lynx range. We found that only 1 relationship met our initial expectations (Table 1); when the number of Canada lynx in the boreal forest increased, the area of southern range increased the following year.

\section{Discussion}

We predicted that years with low Canada lynx abundance in the boreal forest were associated with a reduction in the extent of the southern lynx range. We found support for this idea, as it appeared that the southern range dynamics were mostly driven by boreal lynx population dynamics. The probability of harvesting a lynx at the southern periphery was predicted by lynx harvest the year earlier in the core boreal range. We also predicted that areas with high human disturbance, shallow snow, presence of competitors, and with low connectivity to boreal lynx populations were less likely to be occupied as part of the southern range. However, we found that the anthropogenic effect of roads and competition from bobcats and coyotes did not seem to have influenced the southern range of the Canada lynx in Ontario. We did find that areas that had deep winter snow were often found within the southern lynx range. However, this relationship did not vary temporally with the area of the southern lynx range (Table 1). We used this snow depth predictor as an index of climate change, since we thought that the highest impact of climate warming on lynx would be related to the timing of molt of its main prey the snowshoe hare. We also thought that competition would arise in areas with less snow over time and would become more hospitable to coyote and bobcat. However, we found that the average annual snow depth was not driving the temporal dynamics of the lynx southern range in Ontario but is a habitat condition that determines whether lynx will expand into an area.

There was a weak signal for the temporal dynamics of the coyote, but we did not have enough power to detect a significant relationship given number of tests we performed (Table 1). It is quite reasonable to think that the coyote is a competitor because they are generally found across the southern range apart from a few areas within the boreal forest in Ontario (Figure S3). Bobcat on the other hand, occupied a very small area and generally occurred in the southeastern corner of the west and northeast zones (Figure S4). This spatial relationship itself indicates that the bobcat is not responsible for the range contraction in the southeastern zone, since it is rarely found there. Recent finer scale studies suggested segregation between lynx and bobcat (Marrotte et al. 2020b, Morin et al. 2020).

We observed that the southern range of the lynx has recovered from a dramatic decline in the late 1940s (Figure 4). It has never returned however, to the short-lived maxima we observed during the 1960s. More recently, in the period 2012-2017, the range has reached its maximum extent in the west and central zones. After the mid-1980s, the southern range varied less and from 2010 to 2017, seemed to be increasing. Consequently, we did not find the substantial range loss in more recent times that has been observed in parts 
of the contiguous United States (Ruediger et al. 2000), and as in a previous analysis in Ontario (Koen et al. 2014). The stable and somewhat increasing range in Ontario is not unique across the lynx range, since lynx are increasing in numbers in Maine, USA (Simons-Legaard et al. 2016) and the lynx range in British Columbia has been stable since 1935 (Gooliaff and Hodges 2018). It is important to remember however, that the Canada lynx range across all of North America has contracted substantially from its presettlement extent (Laliberte and Ripple 2004).

The extensive contraction in the early part of the time series may have extended from 1938 to 1951 (Figure 2). In fact, de Vos and Matel (1952) noted that lynx occurrences were rare at this time and the range was also gradually shrinking. They attributed this decline to ecological changes and overharvesting. The decline prompted the closing of lynx trapping during 1951-1952 season and a quota system for lynx was established and trapping was reopened the next year (de Vos and Matel 1952). At the same time, in all of Canada, harvest dropped from 33,054 pelts in 1925 to only 3,734 lynx pelts in 1949 (de Vos and Matel 1952). Lynx fur returns for each jurisdiction in Canada were an order of magnitude lower during the population crash. In approximately the same period, lynx occurrences and harvest in Wisconsin, Minnesota and Michigan also dropped (McKelvey 2000).

Immediately after this large continental wide population crash and subsequent range contraction, the southern range in Ontario expanded almost 8-fold (Figure 4). The ranged peaked in 1963-1964 and lynx were being harvested more than $100 \mathrm{~km}$ south of the boreal forest in southern Ontario for almost 10 years (Figure $3)$. At the same time there was an increase in fur returns and occurrences of lynx in the Great Lakes states immediately south (McKelvey 2000). Similar range expansion and population increase were also present in Alberta, British Columbia, Saskatchewan, Manitoba and Quebec during this period (Todd 1985, McKelvey 2000).

These earlier large fluctuations of the southern lynx range in Ontario and harvest in the Great Lakes states were likely driven by immigration of lynx from the boreal forest (McKelvey 2000, Steury and Murray 2004, Murray et al. 2008). We do see this pattern in our analysis; the southern lynx range changes with the population dynamics of the boreal lynx and this influence decays away from the boreal forest (Table 1). Density dependent dispersal from the boreal forest likely drives the southern lynx range in the northern Great Lakes region. Consequently, southern populations appear to be maintained by emigration from sources in the range core (Steury and Murray 2004, Murray et al. 2008). During peak years, individuals venture south and colonize marginal habitat outside of the boreal forest in Ontario and eventually reach the northern Great Lakes states (Mech 1973, Mech 1980). In more recent times in Ontario, the boreal lynx cycle did not reach extremes as it once did (Figure S5), therefore lynx populations south were no longer being rescued.

There was a period of slow range contraction from 1970 to the late 1990s, where lynx appeared and quickly disappeared from their southern Ontario range. This period is not unique to Ontario, most jurisdictions followed the same pattern (McKelvey 2000). In an earlier study, Koenet al. (2014) noted that the largest range loss happened in this period, but we did not see a continuous decline after 1991 as they did. In fact, the range expanded, and the west and northeast zones were at their largest possible extent and occupied a combined area that was previously unforeseen (Figure 4). Our results probably differ because we were able to assess a longer time series (1972-2010 vs. 1948-2017) and we examined a much larger area.

\section{Conclusion}

The southern range in Ontario is strongly driven by the boreal lynx population dynamics and this may mean that migration of lynx south of the Canada-USA border will become increasingly infrequent, since lynx in the boreal forest of Ontario have not recently reached the high numbers they once did. This is even more true given how average annual snow decreases southward across the border. Canada lynx in the northern US Great Lakes states are likely to require populations that are locally sustained, rather than maintained through a rescue effect, as we anticipate that sufficient southward migration will continue to be rare in the 
future due to reduced amplitude of lynx fluctuations and changing environmental conditions.

\section{References}

Aubry, K.B., Koehler, G.M. and Squires, J.R., 2000. Ecology of Canada lynx in southern boreal forests [Chapter 13]. In: Ruggiero, Leonard F.; Aubry, Keith B.; Buskirk, Steven W.; Koehler, Gary M.; Krebs, Charles J.; McKelvey, Kevin S.; Squires, John R. Ecology and conservation of lynx in the United States. Gen. Tech. Rep. RMRS-GTR-30WWW. Fort Collins, CO: US Department of Agriculture, Forest Service, Rocky Mountain Research Station. p. 373-396., 30, pp.373-396.

Augustin, N.H., Trenkel, V.M., Wood, S.N. and Lorance, P., 2013. Space-time modelling of blue ling for fisheries stock management. Environmetrics, 24(2), pp.109-119.

Bell, G. and Gonzalez, A., 2011. Adaptation and evolutionary rescue in metapopulations experiencing environmental deterioration. Science, 332(6035), pp.1327-1330.

Bendell, J.F. and Young, B., 1995. Populations and habitats of snowshoe hares, ruffed and spruce grouse in the Southern boreal pine forest of Ontario. In 6. International grouse symposium, Udine (Italy), 20-24 Sep 1993. Istituto Nazionale per la Fauna Selvatica.

Berg, N.D., Gese, E.M., Squires, J.R. and Aubry, L.M., 2012. Influence of forest structure on the abundance of snowshoe hares in western Wyoming. The Journal of Wildlife Management, 76(7), pp.1480-1488.

Boucher, Y., Arseneault, D., Sirois, L. and Blais, L., 2009. Logging pattern and landscape changes over the last century at the boreal and deciduous forest transition in Eastern Canada. Landscape Ecology, 24(2), pp.171-184.

Brandt, J.P., 2009. The extent of the North American boreal zone. Environmental Reviews, 17(NA), pp.101-161.

Brown, J.H. and Kodric-Brown, A., 1977. Turnover rates in insular biogeography: effect of immigration on extinction. Ecology, 58(2), pp.445-449.

Bulmer, M.G., 1974. A statistical analysis of the 10-year cycle in Canada. The Journal of Animal Ecology, pp.701-718.

Buskirk, S.W., 2000. Habitat fragmentation and interspecific competition: Implications for lynx conservation [Chapter 4]. In: Ruggiero, Leonard F.; Aubry, Keith B.; Buskirk, Steven W.; Koehler, Gary M.; Krebs, Charles J.; McKelvey, Kevin S.; Squires, John R. Ecology and conservation of lynx in the United States. Gen. Tech. Rep. RMRS-GTR-30WWW. Fort Collins, CO: US Department of Agriculture, Forest Service, Rocky Mountain Research Station. p. 83-100., 30, pp.83-100.

Davis, M.B. and Shaw, R.G., 2001. Range shifts and adaptive responses to Quaternary climate change. Science, 292(5517), pp.673-679.

de Vos, A. and Matel, S.E., 1952. The status of the lynx in Canada, 1920-1952. Journal of Forestry, 50(10), pp.742-745.

de Vos, A., 1964. Range changes of mammals in the Great Lakes region. American Midland Naturalist, pp.210-231.

DeVink, J.M., Berezanski, D. and Imrie, D., 2011. Comments on Brodie and Post: harvest effort: the missing covariate in analyses of furbearer harvest data. Population Ecology, 53(1), pp.261-262.

Dorendorf, R.R., Fix, P.J. and Prugh, L.R., 2016. Motivations of fur trappers in interior Alaska. Human dimensions of wildlife, 21(6), pp.522-537. 
Eickenscheidt, N., Augustin, N.H. and Wellbrock, N., 2018. Spatio-temporal modelling of forest monitoring data: Modelling German tree defoliation data collected between 1989 and 2015 for trend estimation and survey grid examination using GAMMs. arXiv preprint arXiv:1805.09216.

Elton, C. and Nicholson, M., 1942. The ten-year cycle in numbers of the lynx in Canada. The Journal of Animal Ecology, pp.215-244.

Gooliaff, T. and Hodges, K.E., 2018. Historical distributions of bobcats (Lynx rufus ) and Canada lynx (Lynx canadensis) suggest no range shifts in British Columbia, Canada. Canadian Journal of Zoology, 96(12), pp.1299-1308.

Hayne, D.W., 1949. Two methods for estimating population from trapping records. Journal of Mammalogy, 30(4), pp.399-411.

Hiemstra, P. and Hiemstra, M.P., 2013. Package 'automap'. compare, 105, p.10.

Hodges, K.E., 2000. Ecology of snowshoe hares in southern boreal and montane forests [Chapter 7]. In: Ruggiero, Leonard F.; Aubry, Keith B.; Buskirk, Steven W.; Koehler, Gary M.; Krebs, Charles J.; McKelvey, Kevin S.; Squires, John R. Ecology and conservation of lynx in the United States. Gen. Tech. Rep. RMRSGTR-30WWW. Fort Collins, CO: US Department of Agriculture, Forest Service, Rocky Mountain Research Station. p. 163-206., 30, pp.163-206.

Hodges, K.E., Mills, L.S. and Murphy, K.M., 2009. Distribution and abundance of snowshoe hares in Yellowstone National Park. Journal of Mammalogy, 90(4), pp.870-878.

Hoffmann, A.A. and Sgro, C.M., 2011. Climate change and evolutionary adaptation. Nature, 470(7335), p.479.

Hoving, C.L., Harrison, D.J., Krohn, W.B., Jakubas, W.J. and McCollough, M.A., 2004. Canada lynx Lynx canadensis habitat and forest succession in northern Maine, USA. Wildlife biology, 10(1), pp.285-294.

Ivan, J.S., White, G.C. and Shenk, T.M., 2014. Density and demography of snowshoe hares in central Colorado. The Journal of Wildlife Management, 78(4), pp.580-594. Johnson, D.H., 1980. The comparison of usage and availability measurements for evaluating resource preference. Ecology, 61(1), pp.65-71.

Keith, L.B., 1963. Wildlife's ten-year cycle (Vol. 9). Madison: University of Wisconsin Press.

Kerr, J. and Packer, L., 1998. The impact of climate change on mammal diversity in Canada. Environmental Monitoring and Assessment, 49(2-3), pp.263-270.

Koen, E.L., Bowman, J., Murray, D.L. and Wilson, P.J., 2014. Climate change reduces genetic diversity of Canada lynx at the trailing range edge. Ecography, 37(8), pp.754-762.

Krebs, C.J., 2010. Of lemmings and snowshoe hares: the ecology of northern Canada. Proceedings of the Royal Society B: Biological Sciences, 278(1705), pp.481-489.

Krebs, C.J., Boonstra, R., Nams, V., O'Donoghue, M., Hodges, K.E. and Boutin, S., 2001. Estimating snowshoe hare population density from pellet plots: a further evaluation. Canadian Journal of Zoology, 79(1), pp.1-4.

Krebs, C.J., Boutin, S., Boonstra, R. and Sinclair, A.R.E., 1995. Impact of food and predation on the snowshoe hare cycle. Science, 269(5227), p.1112.

Laliberte, A.S. and Ripple, W.J., 2004. Range contractions of North American carnivores and ungulates. BioScience, 54(2), pp.123-138.

Marrotte, R.R., Bowman, J. and Wilson, P.J., 2020a. Climate connectivity of the bobcat in the Great Lakes region. Ecology and Evolution, 10(4), pp.2131-2144. 
Marrotte, R.R., Bowman, J. and Morin, S.J., 2020b. Spatial segregation and habitat partitioning of bobcat and Canada lynx. FACETS, 5(1), pp.503-522.

Marston, M.A., 1942. Winter relations of bobcats to white-tailed deer in Maine. The Journal of Wildlife Management, 6(4), pp.328-337.

McCord, C.M., 1974. Selection of winter habitat by bobcats (Lynx rufus ) on the Quabbin Reservation, Massachusetts. Journal of Mammalogy, 55(2), pp.428-437.

McKelvey, K.S., 2000. History and distribution of lynx in the contiguous United States [Chapter 8]. In: Ruggiero, Leonard F.; Aubry, Keith B.; Buskirk, Steven W.; Koehler, Gary M.; Krebs, Charles J.; McKelvey, Kevin S.; Squires, John R. Ecology and conservation of lynx in the United States. Gen. Tech. Rep. RMRSGTR-30WWW. Fort Collins, CO: US Department of Agriculture, Forest Service, Rocky Mountain Research Station. p. 207-264., 30, pp.207-264.

Mech, L.D., 1973. Canadian lynx invasion of Minnesota. Biological Conservation, 5(2), pp.151-152.

Mech, L.D., 1980. Age, sex, reproduction, and spatial organization of lynxes colonizing northeastern Minnesota. Journal of Mammalogy, 61(2), pp.261-267.

Miller, B.J., Harlow, H.J., Harlow, T.S., Biggins, D. and Ripple, W.J., 2012. Trophic cascades linking wolves (Canis lupus ), coyotes (Canis latrans), and small mammals. Canadian Journal of Zoology, 90(1), pp.70-78.

Morin, S.J., Bowman, J., Marrotte, R.R. and Fortin, M-J., 2020. Fine-scale habitat selection by sympatric Canada lynx and bobcat. Ecology and Evolution

Murray, D.L., 2000. A geographic analysis of snowshoe hare population demography. Canadian Journal of Zoology, 78(7), pp.1207-1217.

Murray, D.L., Steury, T.D. and Roth, J.D., 2008. Assessment of Canada lynx research and conservation needs in the southern range: another kick at the cat. The Journal of Wildlife Management, 72(7), pp.1463-1472.

New Brunswick Endangered Species Regulation. 2013. NB Reg 96-26. Government of New Brunswick, Fredericton. Available from http://canlii.ca/t/521zl [accessed 6 May 2019].

Nicotra, A.B., Atkin, O.K., Bonser, S.P., Davidson, A.M., Finnegan, E.J., Mathesius, U., Poot, P., Purugganan, M.D., Richards, C.L., Valladares, F. and van Kleunen, M., 2010. Plant phenotypic plasticity in a changing climate. Trends in plant science, 15(12), pp.684-692.

Novak, M., 1987a. Furbearer harvests in North America, 1600-1984. Ministry of Natural Resources.

Novak, M., 1987b. Wild furbearer management and conservation in North America. Ontario Ministry of Natural Resources.

O’Donoghue, M., Boutin, S., Krebs, C.J., Zuleta, G., Murray, D.L. and Hofer, E.J., 1998. Functional responses of coyotes and lynx to the snowshoe hare cycle. Ecology, 79(4), pp.1193-1208.

Parker, G., 2001. Status report on the Canada lynx in Nova Scotia. Submitted to Nova Scotia Species at Risk Working Group.

Parker, G.R., Maxwell, J.W., Morton, L.D. and Smith, G.E.J., 1983. The ecology of the lynx (Lynx canadensis ) on Cape Breton Island. Canadian Journal of Zoology, 61(4), pp.770-786.

Poole, K.G., 1994. Characteristics of an unharvested lynx population during a snowshoe hare decline. The Journal of Wildlife Management, pp.608-618.

Priestley, M.B., 1988. Non-linear and non-stationary time series analysis. London: Academic Press, 1988.

R Core Team (2014). R: A language and environment for statistical computing. R Foundation for Statistical Computing, Vienna, Austria. URL http://www.R-project.org/ 
Ripple, W.J., Wirsing, A.J., Beschta, R.L. and Buskirk, S.W., 2011. Can restoring wolves aid in lynx recovery?. Wildlife Society Bulletin, 35(4), pp.514-518.

Rowe, J.S., 1972. Forest regions of Canada. Forest regions of Canada., (1300).

Royama, T., 2012. Analytical population dynamics (Vol. 10). Springer Science \& Business Media.

Ruediger, B., Claar, J., Mighton, S., Naney, B., Rinaldi, T., Wahl, F., Warren, N., Wenger, D., Williamson, A., Lewis, L. and Holt, B., 2000. Canada lynx conservation assessment and strategy.

Ruggiero, L.F., Aubry, K.B., Buskirk, S.W., Koehler, G.M., Krebs, C.J., McKelvey, K.S. and Squires, J.R., 2000. The scientific basis for lynx conservation: qualified insights. Ecology and conservation of lynx in the United States. University Press of Colorado, Boulder, USA, pp.443-454.

Schloss, C.A., Nuñez, T.A. and Lawler, J.J., 2012. Dispersal will limit ability of mammals to track climate change in the Western Hemisphere. Proceedings of the National Academy of Sciences, 109(22), pp.8606-8611.

Scully, A.E., Fisher, S., Miller, D.A. and Thornton, D.H., 2018. Influence of biotic interactions on the distribution of Canada lynx (Lynx canadensis ) at the southern edge of their range. Journal of Mammalogy, 99(4), pp.760-772.

Sexton, J.P., Montiel, J., Shay, J.E., Stephens, M.R. and Slatyer, R.A., 2017. Evolution of ecological niche breadth. Annual Review of Ecology, Evolution, and Systematics, 48, pp.183-206.

Simons-Legaard, E.M., Harrison, D.J. and Legaard, K.R., 2016. Habitat monitoring and projections for Canada lynx: linking the Landsat archive with carnivore occurrence and prey density. Journal of Applied Ecology, 53(4), pp.1260-1269.

Steury, T.D. and Murray, D.L., 2004. Modeling the reintroduction of lynx to the southern portion of its range. Biological Conservation, 117(2), pp.127-141.

Thomas, C.D., 2010. Climate, climate change and range boundaries. Diversity and Distributions, 16(3), pp.488-495.

Todd, A.W., 1985. The Canada lynx: ecology and management. Canadian Trapper, 13(21), pp.15-20.

Travis, J.M., Delgado, M., Bocedi, G., Baguette, M., Bartoń, K., Bonte, D., Boulangeat, I., Hodgson, J.A., Kubisch, A., Penteriani, V. and Saastamoinen, M., 2013. Dispersal and species' responses to climate change. Oikos, 122(11), pp.1532-1540.

US Fish and Wildlife Service, 2000. Endangered and threatened wildlife and plants; determination of threatened status for the contiguous US distinct population segment of the Canada lynx and related rule; final rule. Federal Register, 65(58), pp.16051-16086.

US Fish and Wildlife Service, 2017. Species status assessment for the Canada lynx (Lynx canadensis ) Contiguous United States Distinct Population Segment.

Valladares, F., Matesanz, S., Guilhaumon, F., Araújo, M.B., Balaguer, L., Benito-Garzon, M., Cornwell, W., Gianoli, E., van Kleunen, M., Naya, D.E. and Nicotra, A.B., 2014. The effects of phenotypic plasticity and local adaptation on forecasts of species range shifts under climate change. Ecology letters, 17(11), pp.1351-1364.

Viljugrein, H., Lingjaerde, O.C., Stenseth, N.C. and Boyce, M.S., 2001. Spatio-temporal patterns of mink and muskrat in Canada during a quarter century. Journal of Animal Ecology, 70(4), pp.671-682.

Visser, M.E., 2008. Keeping up with a warming world; assessing the rate of adaptation to climate change. Proceedings of the Royal Society B: Biological Sciences, 275(1635), pp.649-659.

Walther, G.R., Post, E., Convey, P., Menzel, A., Parmesan, C., Beebee, T.J., Fromentin, J.M., HoeghGuldberg, O. and Bairlein, F., 2002. Ecological responses to recent climate change. Nature, 416(6879), 
p.389.

Walpole, A.A., Bowman, J., Murray, D.L. and Wilson, P.J., 2012. Functional connectivity of lynx at their southern range periphery in Ontario, Canada. Landscape Ecology, 27(5), pp.761-773.

Warren, R., Bisset, A.R., Pond, B. and Voigt, D., 1998. The Snow Network for Ontario Wildlife. Ontario Ministry of Natural Resources.(Queen's Printer for Ontario: Peterborough, ON.).

Webb, S.M., Davidson, D.J. and Boyce, M.S., 2008. Trapper attitudes and industrial development on registered traplines in west-central Alberta. Human Dimensions of Wildlife, 13(2), pp.115-126.

Williams, S.E., Shoo, L.P., Isaac, J.L., Hoffmann, A.A. and Langham, G., 2008. Towards an integrated framework for assessing the vulnerability of species to climate change. PLoS biology, 6(12), p.e325.

Wood, S.N., 2011. Fast stable restricted maximum likelihood and marginal likelihood estimation of semiparametric generalized linear models. Journal of the Royal Statistical Society: Series B (Statistical Methodology), 73(1), pp.3-36.

Wood, S.N., Scheipl, F. and Faraway, J.J., 2013. Straightforward intermediate rank tensor product smoothing in mixed models. Statistics and Computing, 23(3), pp.341-360.

Zhou, S., Campbell, R.A. and Hoyle, S.D., 2019. Catch per unit effort standardization using spatio-temporal models for Australia's Eastern Tuna and Billfish Fishery. ICES Journal of Marine Science.

Zahratka, J.L. and Shenk, T.M., 2008. Population estimates of snowshoe hares in the southern Rocky Mountains. The Journal of Wildlife Management, 72(4), pp.906-912

Zimova, M., Mills, L.S. and Nowak, J.J., 2016. High fitness costs of climate change-induced camouflage mismatch. Ecology Letters, 19(3), pp.299-307.

\section{Tables}

Table 1. Spatial and temporal relationships. Values in bold face are significant. Two-tailed p-values were calculated from 9999 permutations. Spatial relationships are partial correlations. Temporal p-values were adjusted with a Bonferroni correction. We only reported the lags that had the absolute highest coefficient. However, all other lags had an adjusted p-value $>0.05$. All partial correlation coefficients are Spearman's rank correlation coefficient and temporal correlations are Pearson's correlation coefficients.

\begin{tabular}{|c|c|c|c|c|c|c|c|}
\hline Covariates & Expected relationship & Spatial & Spatial & Temporal & Temporal & Temporal & $\mathbf{T e}$ \\
\hline Distance boreal forest & - & $\begin{array}{l}\Pi \alpha \rho \tau l \alpha \lambda \rho \\
-0.336\end{array}$ & $\begin{array}{l}\text { Prob. } \\
0.008\end{array}$ & P & Lag & Prob. & \\
\hline Distance nearest road & + & 0.189 & 0.144 & & & & \\
\hline Average annual SDI & + & 0.454 & 0.000 & 0.129 & 0 & 1.000 & \\
\hline Bobcat presence & - & 0.036 & 0.783 & -0.228 & 0 & 1.000 & \\
\hline Coyote presence & - & -0.071 & 0.591 & -0.292 & 0 & 0.402 & \\
\hline Average hare pellets & + & & & 0.337 & 1 & 1.000 & \\
\hline Boreal lynx harvested & + & & & 0.504 & 1 & 0.003 & \\
\hline
\end{tabular}




\section{Figures}

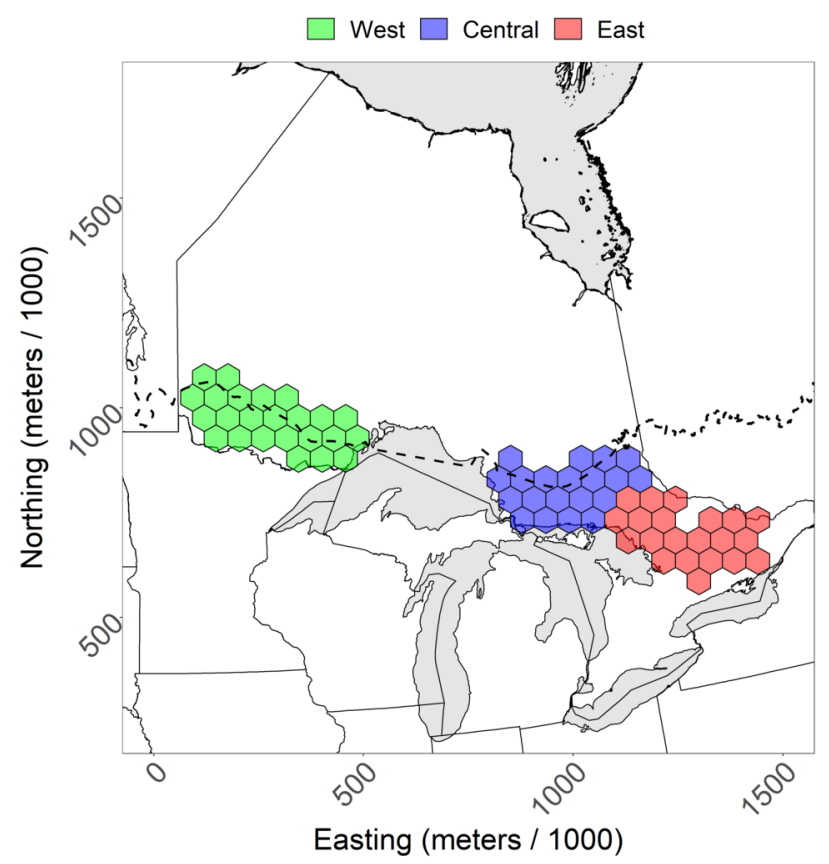

Figure 1. Sampling units in the southern Canada lynx range in Ontario, Canada used to estimate the probability of harvesting a lynx between 1948-2017. The black line is the southern limit of the boreal forest by Brandt (2009). Spatial layers for administrative boundaries were gathered from the Database of Global Administrative Areas (https://gadm.org/).

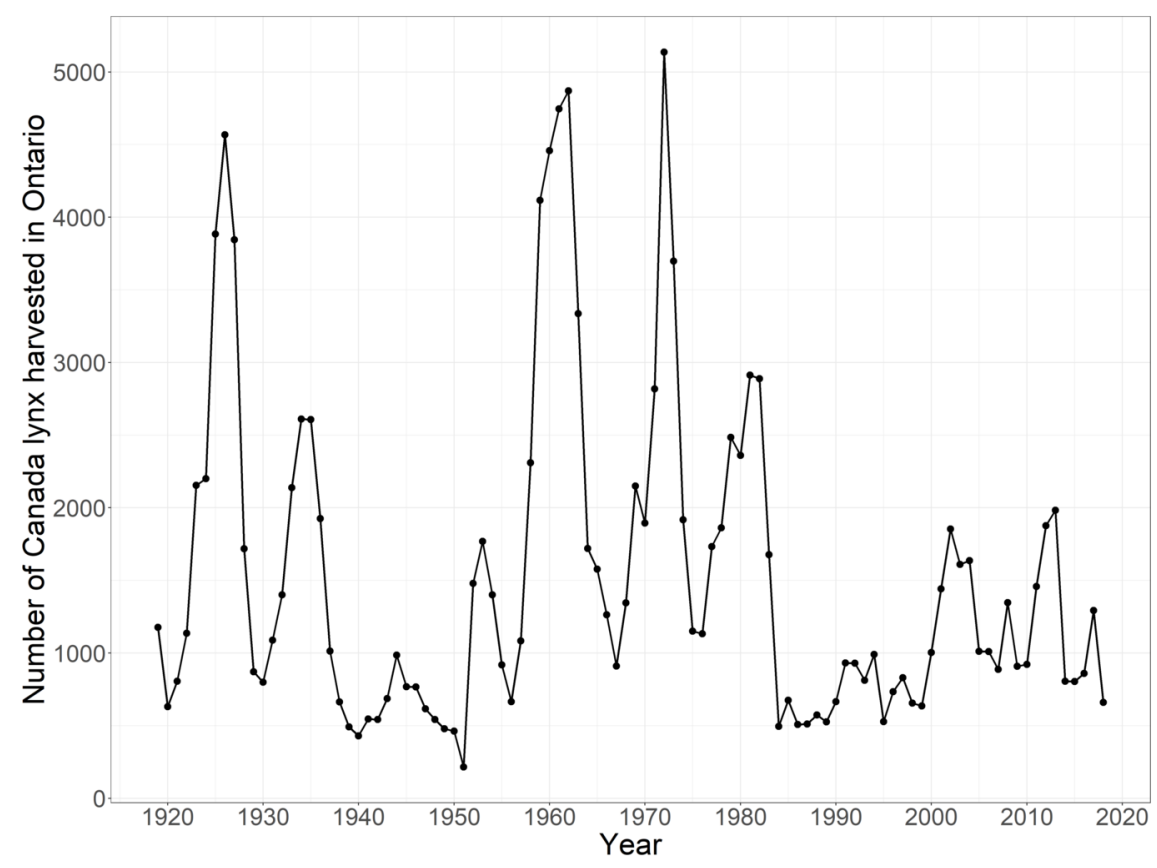


Figure 2. Number of Canada lynx harvested in Ontario, Canada between 1919-2018. Values earlier than 1947 were from Novak (1987a and 1987b). Later values were aggregated from the Ontario fur returns that were used in this study.

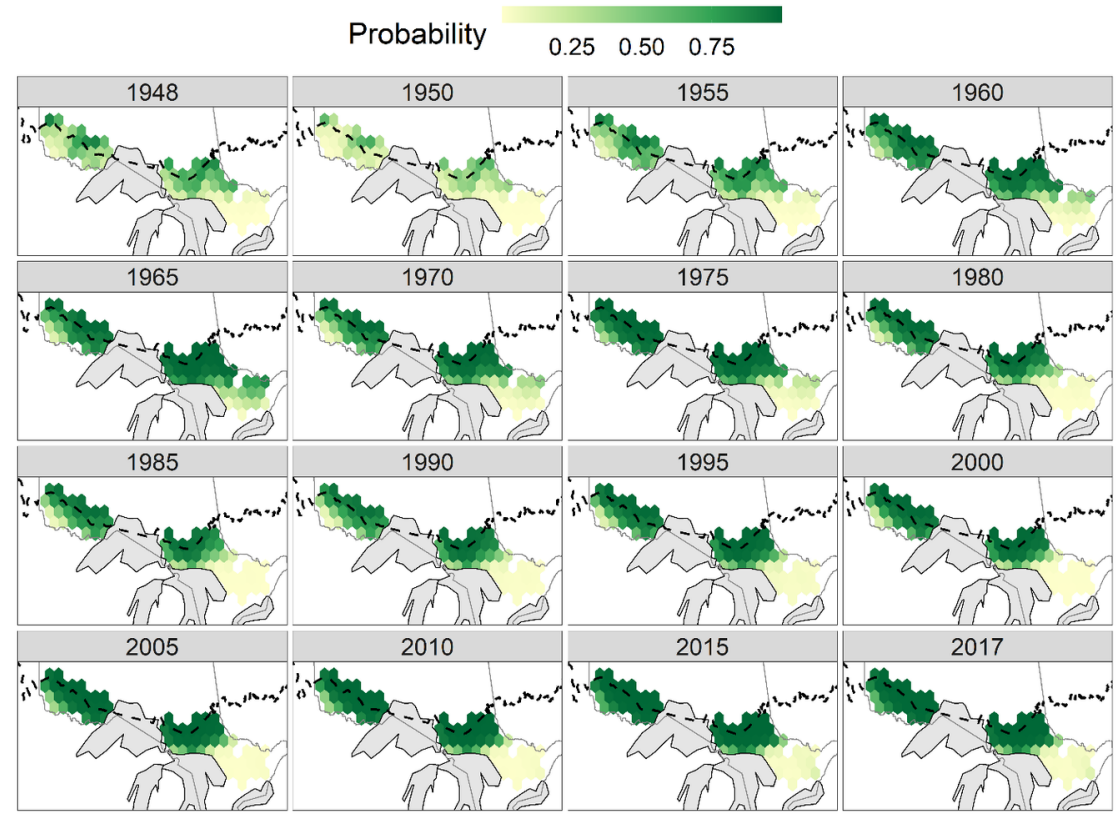

Figure 3. Spatial-temporal pattern of the probability of harvesting a Canada lynx from 1948 to 2017 in Ontario, Canada. The black line is the boreal forest southern limit by Brandt (2009). Spatial layers for administrative boundaries were gathered from the Database of Global Administrative Areas (https://gadm.org/).

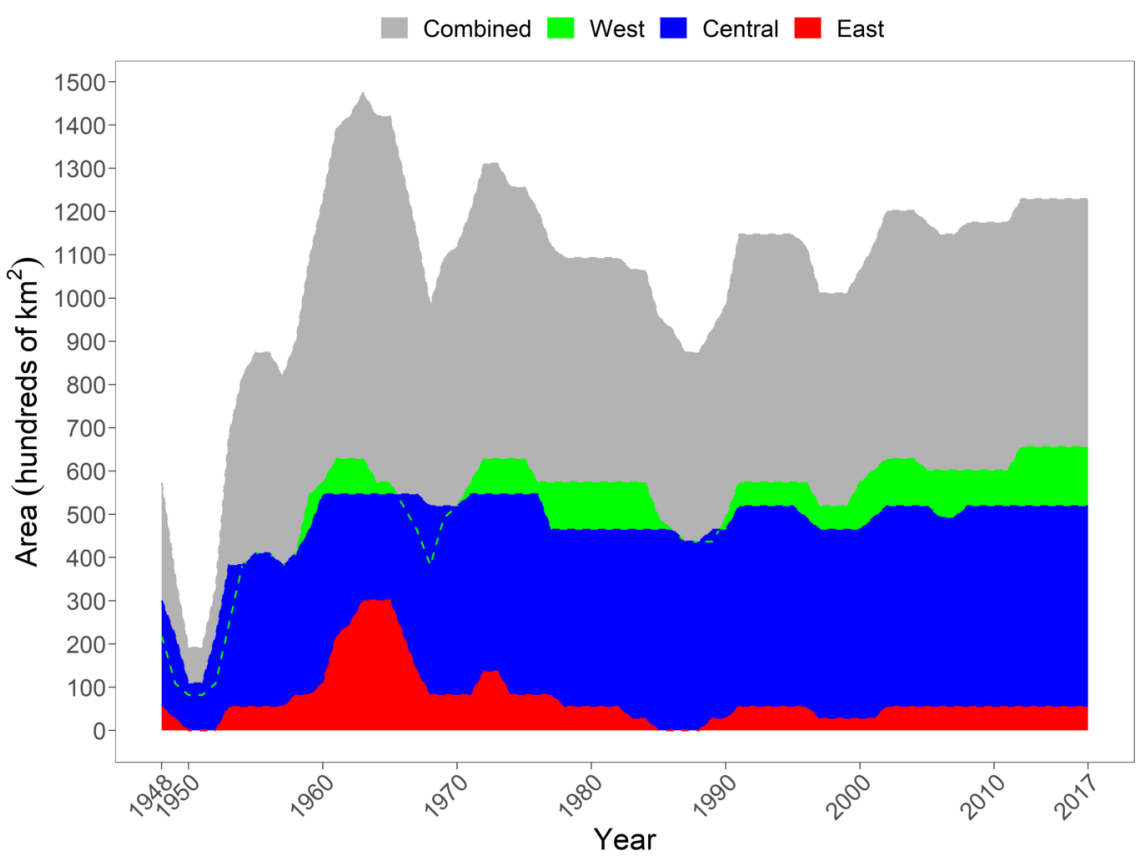


Figure 4. Area of the Canada lynx southern range in Ontario, Canada between 1948-2017. The maximum area of the west, northeast and southeast zone was $65,548.2,54,623.5$ and $57,354.7 \mathrm{~km}^{2}$. The area was calculated by summing the area of the sampling units (hexagons) that had a probability of harvesting a lynx over 0.5 .

\section{Supplemental Material}

Table S1. Summaries of models used to explain the probability of harvesting a lynx while accounting for harvest effort across sampling units in the southern lynx range between 1948-2017 in Ontario, Canada. Covariates unrelated to animals harvested were also included in each of these models. These were the total number of trapping units, the area occupied by those trapping units and the average pelt price. The spatiotemporal pattern was modelled with a tensor product smoother. We modelled the year of harvest with a cubic regression smoother and the spatial process was modelled with a thin plate smoother on the geographic coordinates or with a Markov random field smoother using the neighborhood structure. Harvest-based effort covariates were $\ln$ transformed. MRF is Markov Random Field and TP is Thin Plate smoother.

\begin{tabular}{lllll}
\hline Rank & Harvest-based Covariate* & Spatial Smoother & Relative Maximum Likelihood & Proportion Devianc \\
\hline 1 & Total Harvest & TP & 1521.568 & 0.541 \\
2 & Average Total Harvest & TP & 1533.745 & 0.538 \\
3 & Total harvested Density & TP & 1543.371 & 0.536 \\
4 & Marten Harvest Density & TP & 1549.976 & 0.535 \\
5 & Marten Harvest & TP & 1555.515 & 0.534 \\
6 & Marten Average Harvest & TP & 1557.371 & 0.533 \\
7 & Total Harvest & MRF & 1611.840 & 0.583 \\
8 & Average Total Harvest & MRF & 1618.995 & 0.584 \\
9 & Total harvested Density & MRF & 1624.088 & 0.585 \\
10 & Marten Harvest Density & MRF & 1616.483 & 0.582 \\
11 & Marten Average Harvest & MRF & 1620.269 & 0.583 \\
12 & Marten Harvest & MRF & 1620.067 & 0.582 \\
\hline
\end{tabular}



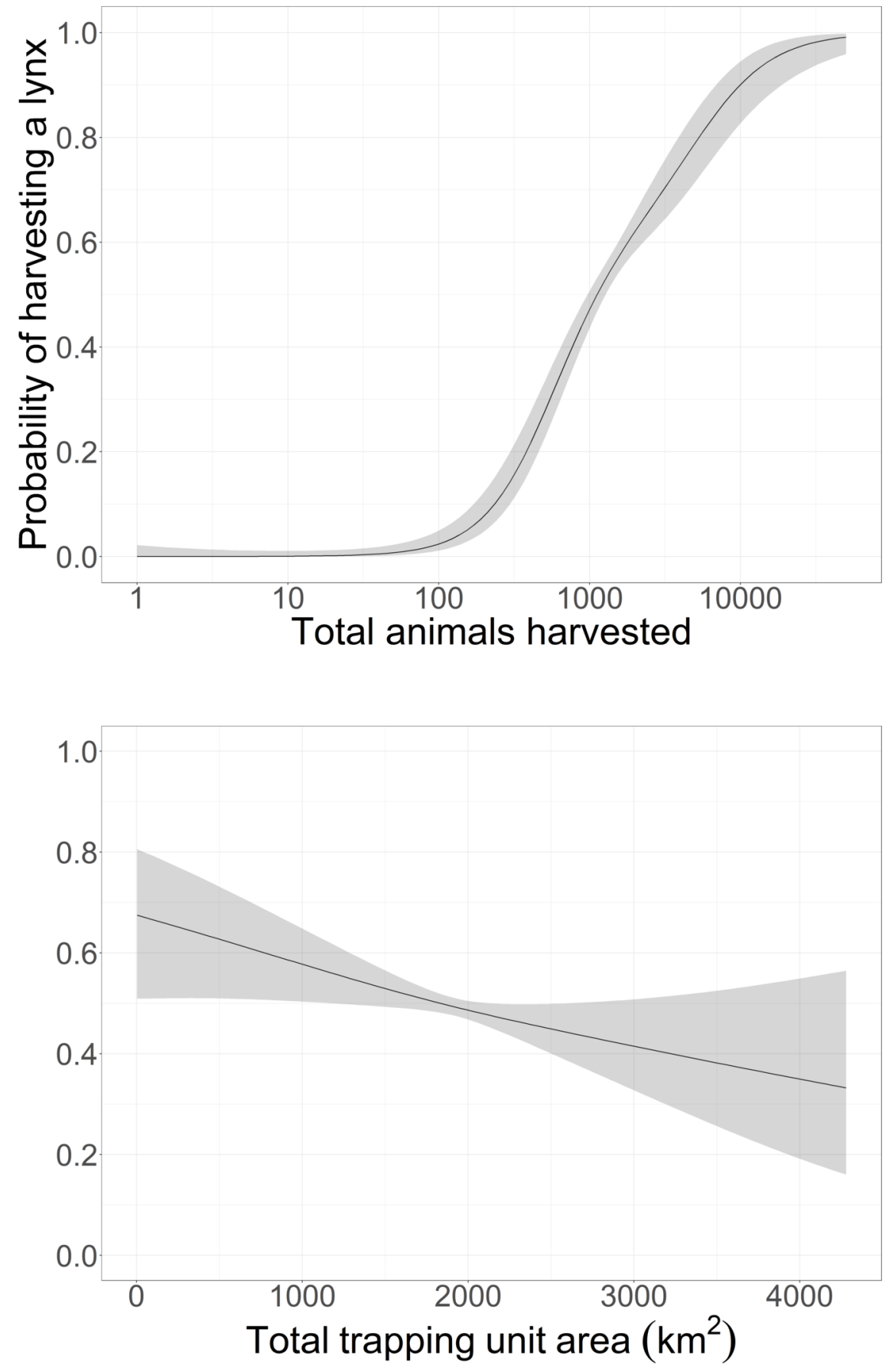

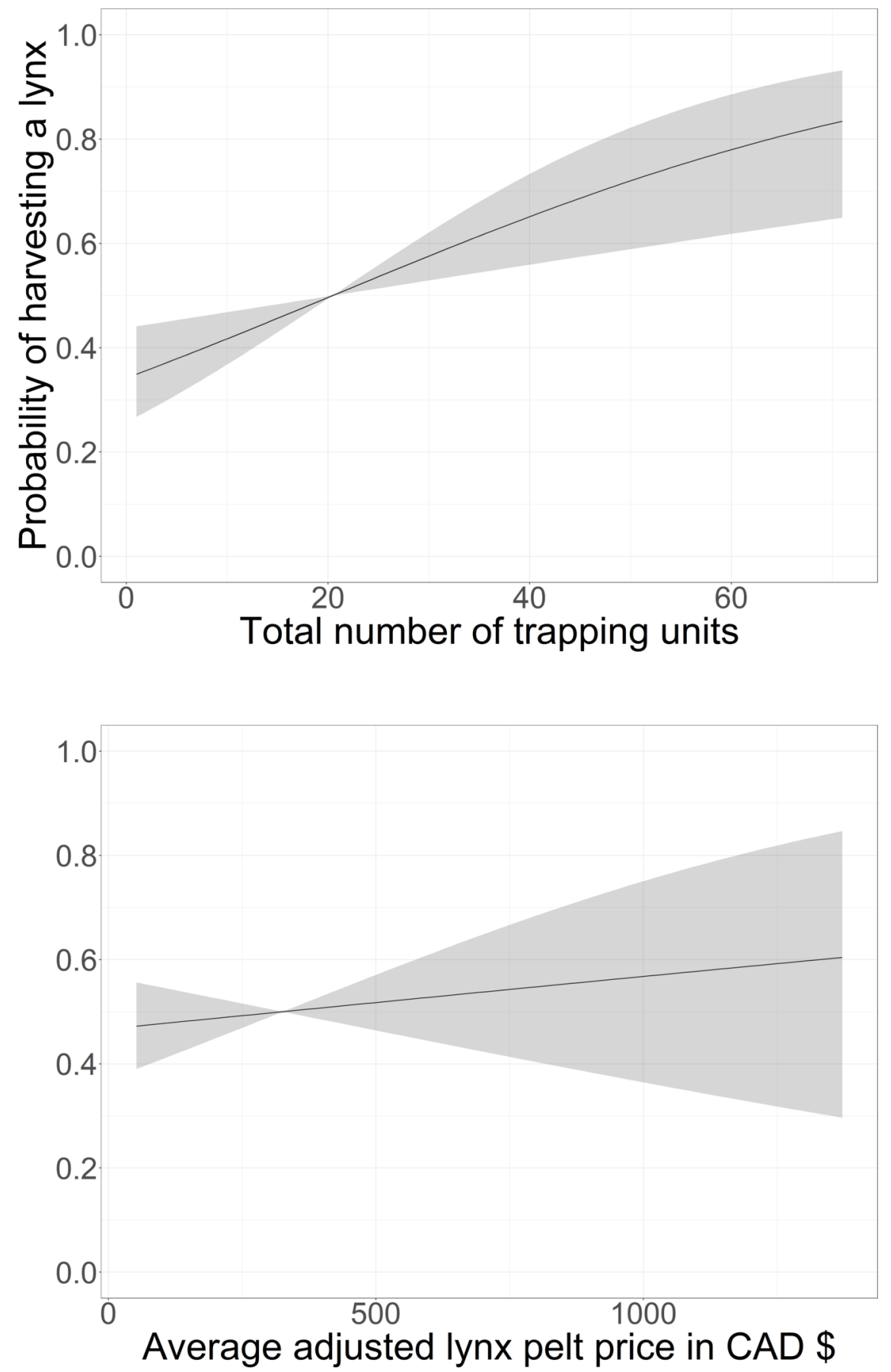

Figure S1. Effort covariates for predicting the probability of harvesting a Canada lynx between 1948 and 2017 across sampling units south of the boreal forest in Ontario, Canada. 


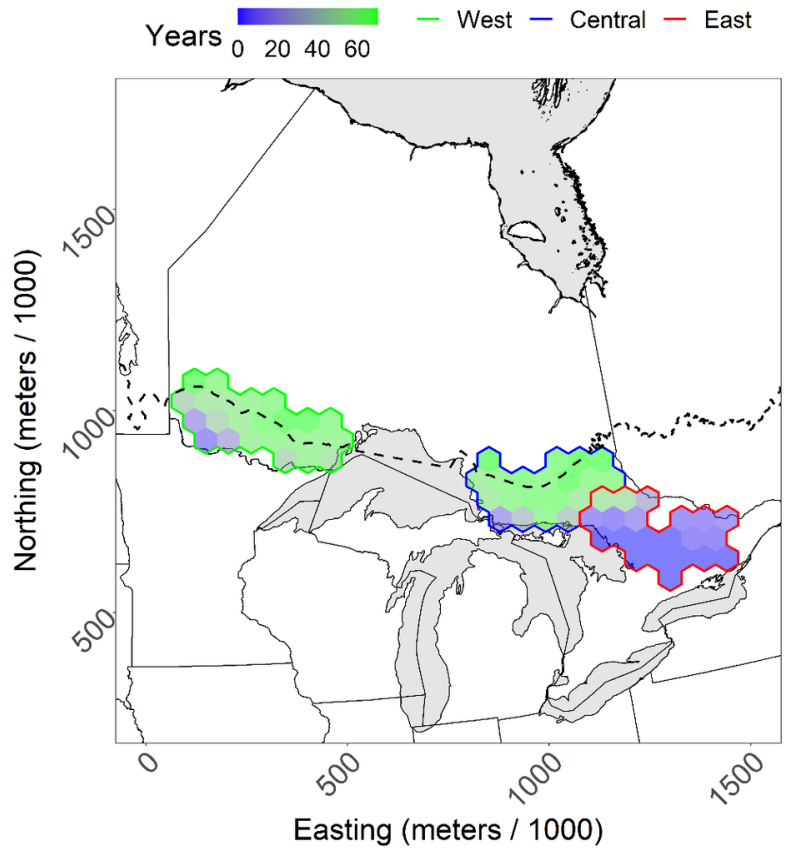

Figure S2. Frequency or number of years that each sampling unit was part of the southern Canada lynx range between 1948-2017 south of the boreal forest in Ontario, Canada. The black line is the boreal forest southern limit by Brandt (2009). Spatial layers for administrative boundaries were gathered from the Database of Global Administrative Areas (https://gadm.org/). 


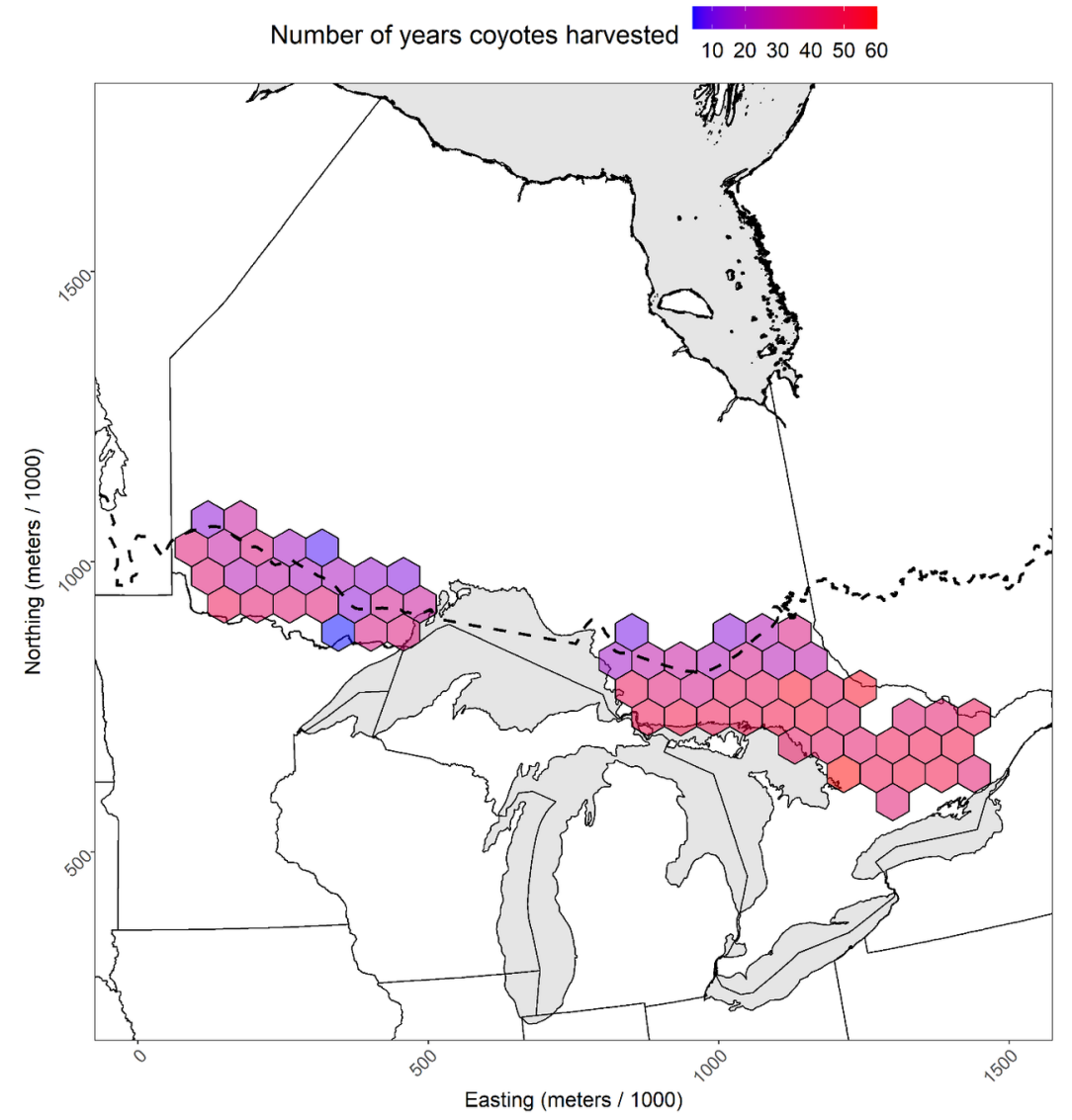

Figure S3. Number of years that coyotes were harvested within sampling units in the southern range of the Canada lynx in Ontario, Canada between 1948 and 2017. The black line is the boreal forest southern limit by Brandt (2009). Spatial layers for administrative boundaries were gathered from the Database of Global Administrative Areas (https://gadm.org/). 


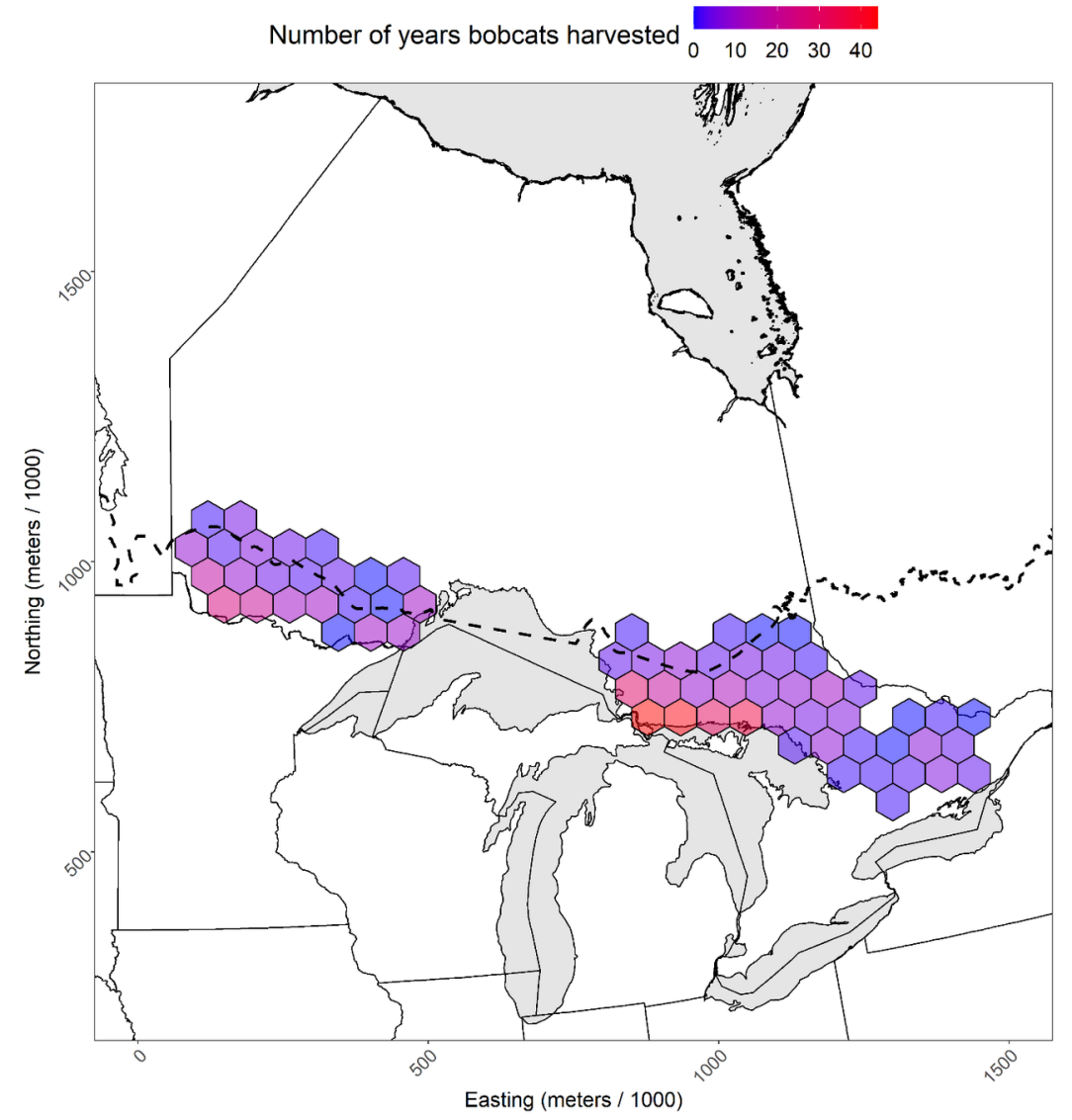

Figure S4. Number of years that bobcats were harvested within sampling units in the southern range of the Canada lynx in Ontario, Canada between 1948 and 2017. The black line is the boreal forest southern limit by Brandt (2009). Spatial layers for administrative boundaries were gathered from the Database of Global Administrative Areas (https://gadm.org/). 


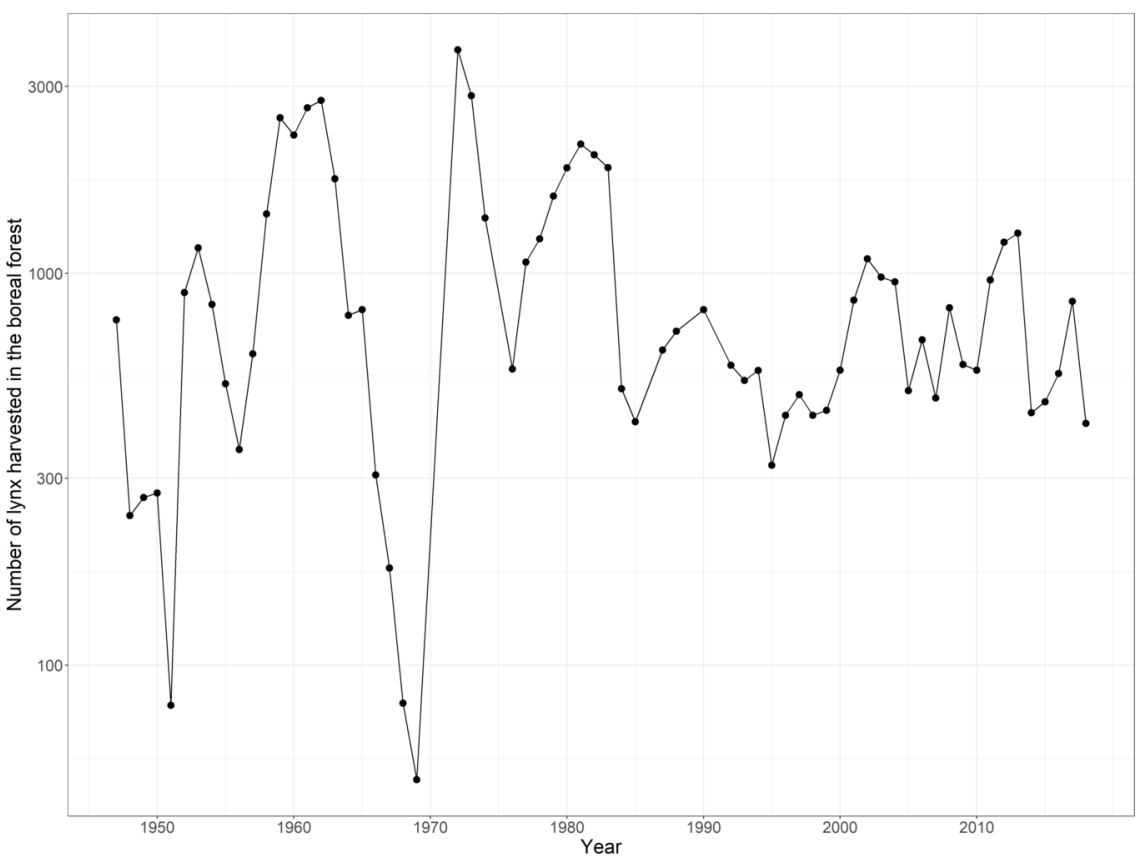

Figure S5. Number of Canada lynx harvested in the boreal forest of Ontario from 1948 to 2018. Records used to estimate the southern range at the southern boundary of the boreal forest were removed. 